\title{
Analisis Kebutuhan Ruang Parkir (Off Street Parking) di Kawasan Pasar Pucang Surabaya
}

\author{
Zaldy Purwa, Hera Widyastuti, dan Cahya Buana \\ Departemen Teknik Sipil, Institut Teknologi Sepuluh Nopember (ITS) \\ Corresponding Author: h_w_dyas2004@yahoo.co.uk
}

\section{ARTIKEL INFO}

\section{Informasi Artikel}

Artikel masuk: 6-8-19

Artikel revisi: 26-12-19

Artikel diterima: 26-12-19

\section{Kata Kunci}

Off Street Parking, Karakteristik Parkir, Kebutuhan Ruang Parkir, Derajat Jenuh, Pasar Pucang.

\begin{abstract}
ABSTRAK
Kota Surabaya adalah Ibukota Provinsi Jawa Timur, Indonesia yang merupakan kota terbesar kedua di Indonesia setelah Jakarta. Dengan jumlah penduduk yang hampir 3 juta jiwa (Sumber: Badan Pusat Statistik). Sebagai kota metropolitan, Surabaya menjadi pusat kegiatan perekonomian di daerah Jawa Timur dan sekitarnya. Salah satu kegiatan perekonomian di Surabaya berada di kawasan pasar Pucang Surabaya. . Wilayah Pasar Pucang yang berpotensi menjadi salah satu pasar yang diminati sebagian besar masyarakat Surabaya tidak diimbangi dengan fasilitas parkir kendaraan (off street parking) yang memadai. Masyarakat yang ingin datang ke kawasan Pasar Pucang khususnya yang menggunakan mobil harus memarkirkan kendaraannya di badan jalan sehingga lebar efektif jalan menjadi berkurang dan dapat mengakibatkan kepadatan arus lalu lintas. Untuk itu dibutuhkan perencanaan ulang gedung parkir agar dapat menampung volume kendaraan yang parkir di badan jalan. Data yang dibutuhkan untuk perencanaan ini adalah data primer yaitu dengan melakukan pencatatan pelat nomor kendaraan yang parkir dan juga survei volume arus lalu lintas (counting). Dari analisa ini, dapat diperoleh volume kendaraan dan juga karakteristik pengguna parkir. Tahap perencanaan, perencanaan beberapa layout rencana ruang parkir termasuk sirkulasi kendaraan dan tata cara untuk parkir. Dari hasil analisis, didapatkan volume puncak arus lalu lintas di Jalan Pucang Anom sebesar 1088 skr/jam dengan tingkat derajat kejenuhan sebesar 0,99. Sementara untuk analisis karakteristik parkir didapatkan volume total kendaraan mobil sebesar 301 mobil dengan akumulasi parkir maksimal sebesar 41 mobil sementara untuk motor sebesar 412 motor dengan akumulasi parkir maksimal sebesar 80 motor.
\end{abstract}

\section{PENDAHULUAN}

Kota Surabaya adalah ibukota provinsi Jawa Timur, Indonesia. Surabaya merupakan kota terbesar kedua di Indonesia setelah Jakarta. Dengan jumlah penduduk metropolis yang hampir 3 juta jiwa, sebagai kota metropolitan Surabaya menjadi pusat kegiatan perekonomian di daerah Jawa Timur dan sekitarnya. Sebagian besar penduduknya bergerak dalam bidang jasa, industri, dan perdagangan sehingga jarang ditemukan lahan persawahan. Banyak sekali masyarakat di luar Kota Surabaya yang datang dengan alasan pekerjaan ataupun hanya untuk berlibur pada setiap harinya. Ini menyebabkan jalanan di Kota Surabaya semakin padat. Kenaikan jumlah kendaraan bermotor tidak seimbang dengan ketersedian sarana dan prasarana yang memadai, sehingga perkembangan arus lalu lintas menjadi padat dan tidak teratur. Salah satu prasarana transportasi adalah lahan parkir. Areal parkir merupakan salah satu prasarana transportasi yang harus ditata dan dikelola dengan baik agar dapat memenuhi kebutuhan ruang parkir, baik itu areal on street parking maupun off street parking.
Kegagalan dalam pengendalian perparkiran dapat mengakibatkan turunnya kapasitas jalan, terhambatnya lalu lintas, penggunaan jalan menjadi tidak efektif, pencemaran lingkungan (polusi) yang diakibatkan oleh antrian kendaraan pada suatu ruas jalan tertentu dalam keadaan mesin hidup dan bahkan dapat menyebabkan kecelakaan lalu lintas [1].

Kawasan Pasar Pucang Anom Surabaya merupakan salah salah satu pusat tempat perbelanjaan yang ramai dikunjungi oleh masyarakat Surabaya. Sayangnya, banyaknya pengunjung yang datang tidak diikuti dengan fasilitas parkir kendaraan (off street parking) yang memadai. Fasilitas lahan parkir yang tersedia di Pasar Pucang Anom hanya tersedia untuk kendaraan roda dua saja. Sementara, para pengunjung yang menggunakan mobil harus parkir di badan jalan di sepanjang Pasar Pucang. Hal ini menyebabkan berkurangnya efektifitas lebar jalan di sepanjang Pasar Pucang Surabaya. Ditambah dengan lahan parkir di badan jalan yang tidak begitu luas, pengguna parkir harus saling bergantian dengan pengguna lainnya. Pada saat pergantian kendaraan (manuver) 
tersebut dapat mengakibatkan kepadatan arus lalu lintas di kawasan tersebut.

Sehubungan dengan adanya masalah tersebut, pada studi ini akan dilakukan perencanaan ulang gedung parkir sebagai solusi untuk menampung kendaraan yang parkir di badan jalan (on street parking). Gedung parkir ini direncanakan untuk dapat digunakan bagi seluruh pengunjung maupun penjual di Pasar Pucang Surabaya.

\section{METODE PENELITIAN}

Langkah-langkah yang dilakukan untuk mengerjakan studi ini dapat dilihat melalui diagram alir. Untuk gambar diagaram alir dapat pada Gambar 1.

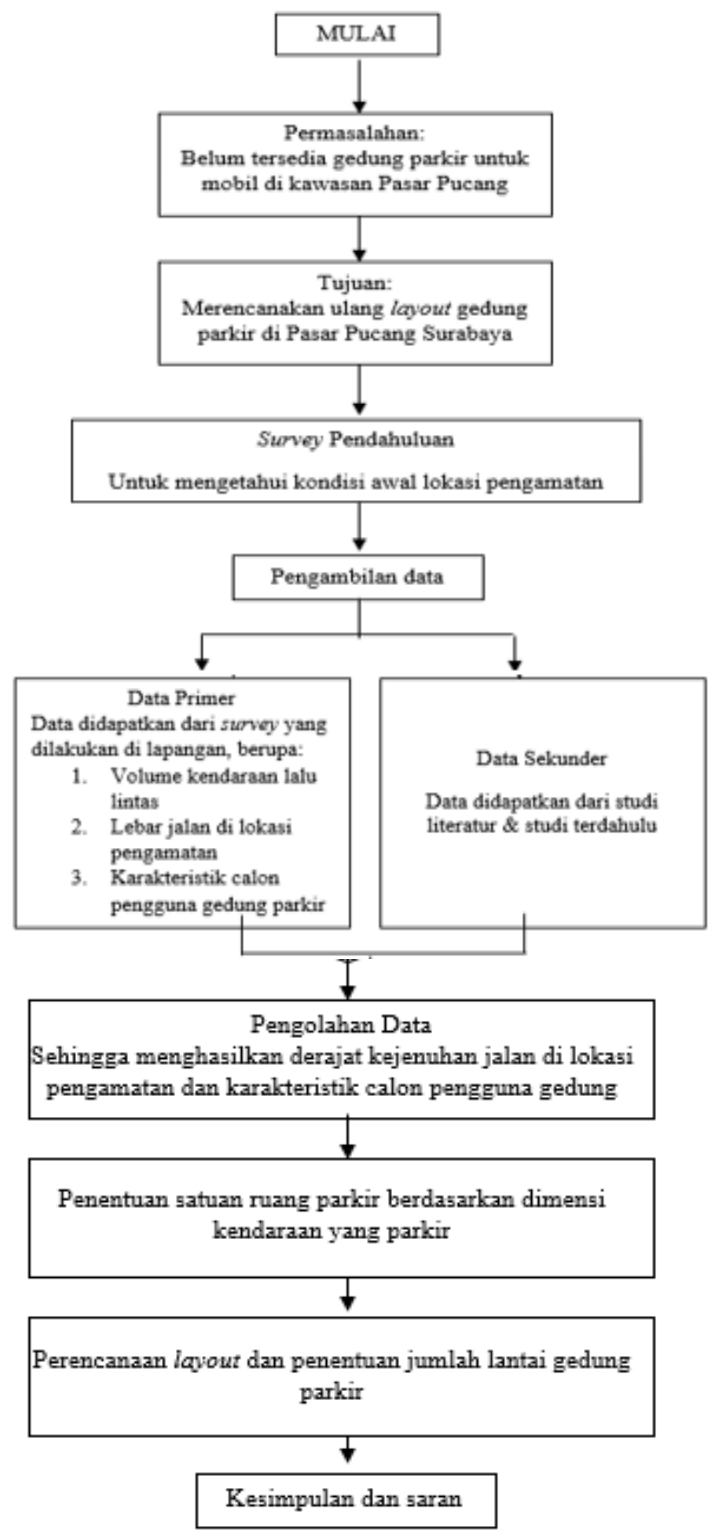

Gambar 1. Diagram Alir Metode Penelitian.

\section{HASIL DAN PEMBAHASAN}

\section{A. Data Volume Lalu Lintas}

Data arus dan komposisi lalu lintas didapatkan melalui survei langsung di lapangan. Survei dilakukan pada hari Rabu, 24 Oktober 2018 yang dimulai pukul $07.00-09.00$ dan 13.00 - 15.30. Pemilihan rentang waktu tersebut berdasarkan dengan jam masuk sekolah dan pulang sekolah karena di sekitar daerah tersebut terdapat beberapa sekolah (SD, SMP, SMA). Selain itu juga, pada rentang waktu tersebut merupakan jam buka dan tutup toko dan pasar di wilayah tersebut. Survei lalu lintas dilaksanakan dengan cara mencatat jumlah kendaraan setip interval 15 menit.

\begin{tabular}{|c|c|c|c|c|c|c|c|c|c|c|c|}
\hline \multirow{2}{*}{ Arah } & \multirow{2}{*}{ Waktu } & \multirow{2}{*}{$\mathrm{KR}$} & \multirow{2}{*}{ KB } & \multirow{2}{*}{ SM } & \multicolumn{3}{|c|}{ Smp/jam } & \multirow{2}{*}{\multicolumn{3}{|c|}{ volume kendarazan smp/jam }} & \multirow{2}{*}{ Volume Tota } \\
\hline & & & & & 1 & 1,3 & 0,5 & & & & \\
\hline \multirow{21}{*}{ Timur-Barat } & $07.00-07.15$ & 27 & 0 & 116 & 27 & 0 & 58 & & & & \\
\hline & $07.15-07.30$ & 32 & 0 & 137 & 32 & 0 & 68,5 & & & & \\
\hline & $07.30-07.45$ & 24 & 0 & 134 & 24 & 0 & 67 & & & & \\
\hline & $07.45 \cdot 08.00$ & 21 & 0 & 120 & 21 & 0 & 60 & 104 & 0 & 253,5 & 357,5 \\
\hline & $08.00-08.15$ & 11 & 0 & 80 & 11 & 0 & 40 & 88 & 0 & 235,5 & 322,5 \\
\hline & $08.15-08.30$ & 9 & 0 & 46 & 9 & 0 & 23 & 65 & 0 & 190 & 255 \\
\hline & $08.30 \cdot 08.45$ & 8 & 0 & 35 & 8 & 0 & 17,5 & 49 & 0 & 140,5 & 189,5 \\
\hline & $08.45 \cdot 09.00$ & 15 & 0 & 81 & 15 & 0 & 40,5 & 43 & 0 & 121 & 164 \\
\hline & $13.00-13.15$ & 15 & 3 & 72 & 15 & 3,9 & 36 & & & & \\
\hline & $13.15 \cdot 13.30$ & 17 & 2 & 82 & 17 & 2,6 & 41 & & & & \\
\hline & $13.30-13.45$ & 18 & 2 & 100 & 18 & 2,6 & 50 & & & & \\
\hline & $13.45-14.00$ & 16 & 3 & 97 & 16 & 3,9 & 48,5 & 66 & 13 & 175,5 & 254,5 \\
\hline & $14.00-14.15$ & 19 & 1 & 99 & 19 & 1,3 & 49,5 & 70 & 10,4 & 189 & 269,4 \\
\hline & $14.15-14.30$ & 20 & 4 & 107 & 20 & 5,2 & 53,5 & 73 & 13 & 201,5 & 287,5 \\
\hline & 14.30-14.45 & 25 & 2 & 109 & 25 & 2,6 & 54,5 & 80 & 13 & 206 & 299 \\
\hline & $14.45-15.00$ & 30 & 1 & 115 & 30 & 1,3 & 57,5 & 94 & 10,4 & 215 & 319,4 \\
\hline & $15.00-15.15$ & 20 & 1 & 78 & 20 & 1,3 & 39 & 95 & 10,4 & 204,5 & 30,9 \\
\hline & $15.15-15.30$ & 16 & 0 & 86 & 16 & 0 & 43 & 91 & 5,2 & 194 & 290,2 \\
\hline & $14.45-15.00$ & 30 & 1 & 115 & 30 & 1,3 & 57,5 & 96 & 3,9 & 199 & 296,9 \\
\hline & $15.00-15.15$ & 20 & 1 & 78 & 20 & 1,3 & 39 & 86 & 3,9 & 178,5 & 268,4 \\
\hline & \begin{tabular}{ll|}
$15.15-15.30$ \\
\end{tabular} & 16 & 0 & 86 & 16 & 0 & 43 & 82 & 2,6 & 182,5 & 267,1 \\
\hline
\end{tabular}

Berdasarkan Tabel 1, dapat diketahui bahwa besaran volume total puncak pada lajur arah Timur-Barat yaitu terjadi pada pukul 07.45 - 08.00 yaitu sebesar 358 smp/jam.

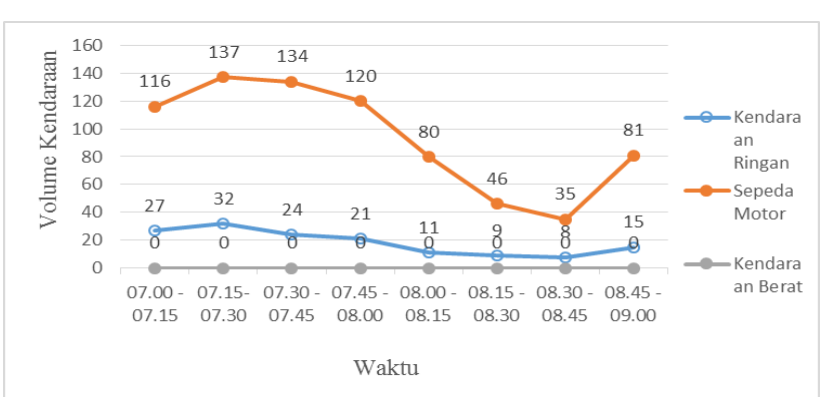

Gambar 2. Grafik Komposisi Kendaraan di Jalan Pucang Anom sesi pertama.

Dari Gambar 2, dapat dilihat grafik yang menunjukan jika volume puncak lajur arah Timur-Barat pada sesi pertama terjadi pada pukul 07.15-07.30 sebesar 137 kendaraan motor dan 32 kendaraan mobil.

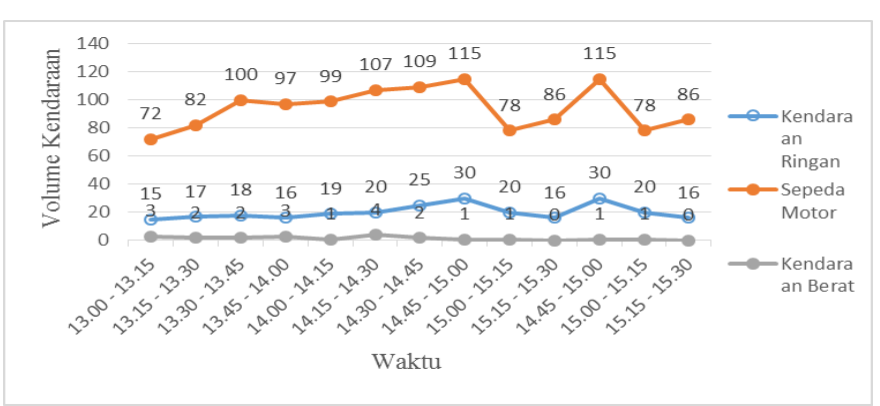

Gambar 3. Grafik Komposisi Kendaraan di Jalan Pucang Anom sesi kedua.

Dari Gambar 3, dapat dilihat grafik yang menunjukan jika volume puncak lajur arah Timur-Barat pada sesi kedua terjadi pada pukul 14.45-15.00 sebesar 115 kendaraan motor dan 30 kendaraan mobil. Akan tetapi 
volume puncak pada sesi kedua ini masih lebih kecil dari volume puncak pada sesi pertama sehingga diambil volume puncak tertinggi yaitu pada sesi pertama.

\begin{tabular}{|c|c|c|c|c|c|c|c|c|c|c|c|c|c|}
\hline \multirow{2}{*}{ Harithngeal } & \multirow{2}{*}{ Jakn } & \multirow{2}{*}{ Arah } & \multirow{2}{*}{ Waktu } & \multirow{2}{*}{ KR } & \multirow{2}{*}{$\mathrm{KB}$} & \multirow{2}{*}{ SM } & \multicolumn{3}{|c|}{ Smpljam } & \multirow{2}{*}{\multicolumn{3}{|c|}{ volume kendarazn smplj.jam }} & \multirow{2}{*}{ Volune Totat } \\
\hline & & & & & & & 1 & 1,3 & 0,5 & & & & \\
\hline \multirow{19}{*}{$\begin{array}{c}\text { Ratu/ } / 24 \\
\text { Othoter } 2018\end{array}$} & \multirow{19}{*}{ Ialan Puang Anom } & \multirow{19}{*}{ Timur-Brart } & $07.00 \cdot 07.15$ & 27 & 0 & 116 & 27 & 0 & 58 & & & & \\
\hline & & & $07.15-0.730$ & 32 & 0 & 137 & 32 & 0 & 68,5 & & & & \\
\hline & & & 0730.07 .45 & 24 & 0 & 134 & 24 & 0 & 67 & & & & \\
\hline & & & $07,45 \cdot 08.00$ & 21 & 0 & 120 & 21 & 0 & 60 & 104 & 0 & 253,5 & 357,5 \\
\hline & & & $08.00-08.15$ & 11 & 0 & 80 & 11 & 0 & 40 & 88 & 0 & 235,5 & 322,5 \\
\hline & & & $08.15 \cdot 0830$ & 9 & 0 & 46 & 9 & 0 & 23 & 65 & 0 & 190 & 255 \\
\hline & & & 0.330 .0845 & 8 & 0 & 35 & 8 & 0 & 17,5 & 49 & 0 & 140,5 & 189,5 \\
\hline & & & $0.85 \cdot 09.0$ & 15 & 0 & 81 & 15 & 0 & 40,5 & 43 & 0 & 121 & 164 \\
\hline & & & & & & & & & & & & & \\
\hline & & & $13.00-13.15$ & 15 & 3 & 72 & 15 & 3,9 & 36 & & & & \\
\hline & & & $13.15 \cdot 13.30$ & 17 & 2 & 82 & 17 & 2,6 & 41 & & & & \\
\hline & & & 1330.13.45 & 18 & 2 & 100 & 18 & 2,6 & 50 & & & & \\
\hline & & & 13.45-14.00 & 16 & 3 & 97 & 16 & 3,9 & 48,5 & 66 & 13 & 175,5 & 254,5 \\
\hline & & & $14000 \cdot 141.15$ & 19 & 1 & 99 & 19 & 1,3 & 49,5 & 70 & 10,4 & 1899 & 269,4 \\
\hline & & & 14.15.14.3.30 & 20 & 4 & 107 & 20 & 5,2 & 53,5 & 73 & 13 & 201,5 & 287,5 \\
\hline & & & 14330.144.45 & 25 & 2 & 109 & 25 & 2,6 & 54,5 & 80 & 13 & 206 & 299 \\
\hline & & & $14.45 \cdot 15.00$ & 30 & 1 & 115 & 30 & 1,3 & 57,5 & 94 & 10,4 & 215 & 319,4 \\
\hline & & & $15.00 \cdot 15.15$ & 20 & 1 & 78 & 20 & 1,3 & 39 & 95 & 10,4 & 20,5 & 399,9 \\
\hline & & & $15.15 \cdot 15.30$ & 16 & 0 & 86 & 16 & 0 & 43 & 91 & 5,2 & 194 & 20,2 \\
\hline
\end{tabular}

Dari Tabel 1 dan 2 dapat disimpulkan bahwa volume lalu lintas maksimum pada ruas Jalan Pucang Anom terjadi pada pukul 07.00 - 08.00 yaitu volume mobil sebesar 357,5 skr/jam ditambah dengan volume motor sebesar $730.5 \mathrm{skr} / \mathrm{jam}$ sehingga didapat total volume sebesar $1088 \mathrm{skr} / \mathrm{jam}$

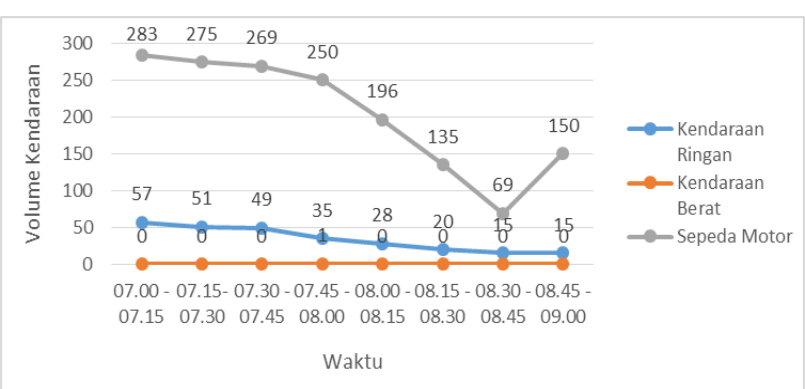

Gambar 4. Grafik Komposisi Kendaraan di Jalan Pucang Anom sesi pertama

Dari Gambar 4, dapat dilihat grafik yang menunjukan jika volume puncak lajur arah Barat-Timur pada sesi pertama terjadi pada pukul 07.00-07.15 sebesar 283 kendaraan motor dan 57 kendaraan mobil.

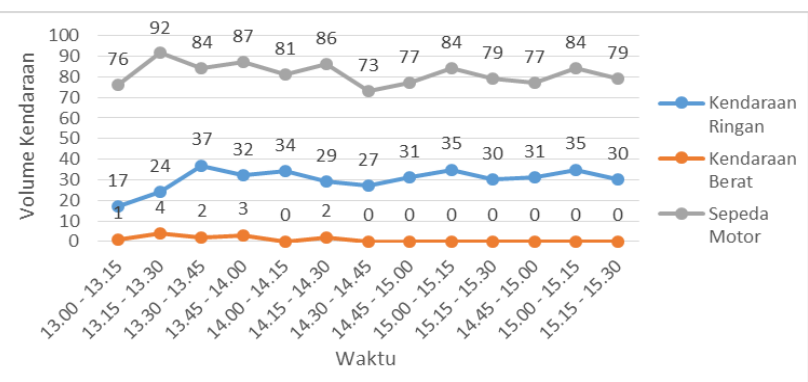

Gambar 5. Grafik Komposisi Kendaraan di Jalan Pucang Anom sesi kedua.

Dari Tabel 1 dan 2 dapat disimpulkan bahwa volume lalu lintas maksimum pada ruas Jalan Pucang Anom terjadi pada pukul 07.00 - 08.00 yaitu volume mobil sebesar 357,5 skr/jam ditambah dengan volume motor sebesar $730.5 \mathrm{skr} / \mathrm{jam}$ sehingga didapat total volume sebesar $1088 \mathrm{skr} / \mathrm{jam}$

\section{B. Kinerja Jalan}

Perhitungan kapasitas ruas Jalan Pucang Anom adalah sebgai berikut:

$$
\begin{aligned}
\mathrm{C}=\mathrm{C} 0 \times \mathrm{FCLJ} \times \mathrm{FCPA} \times \mathrm{FCHS} \times \mathrm{FCUK}[1] \\
=2900 \times 0,56 \times 1 \times 0,68 \times 1 \\
=1104,32 \mathrm{skr} / \mathrm{jam}
\end{aligned}
$$

Setelah didapat kapasitas dan volume pada jam puncak sebesar 1088 skr/jam, maka dapat dihitung derajat kejenuhan (DJ) [1]:

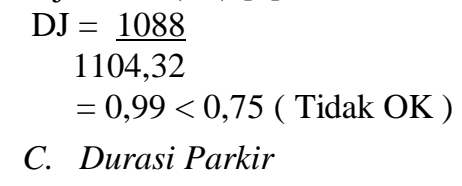

\section{Durasi Parkir}

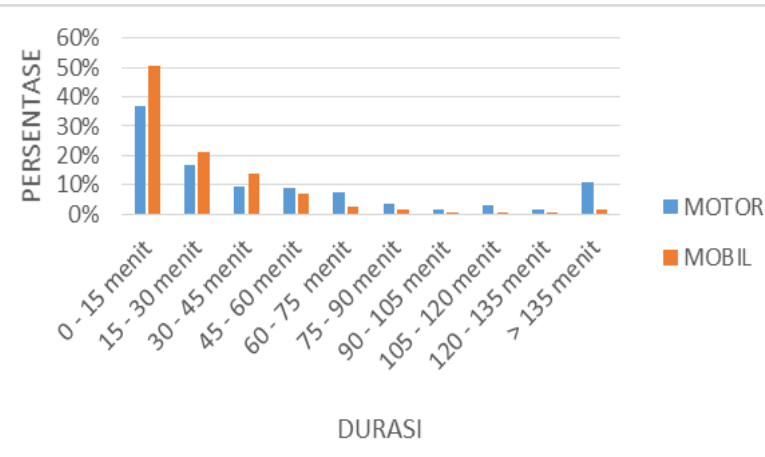

Gambar 6: Grafik Durasi Parkir Kendaraan Mobil dan motor [2]

Dari grafik diatas dapat disimpulkan bahwa sebagian besar motor dan mobil parkir dengan durasi 0-15 menit di kawasan Pasar Pucang.

\section{Akumulasi Parkir}

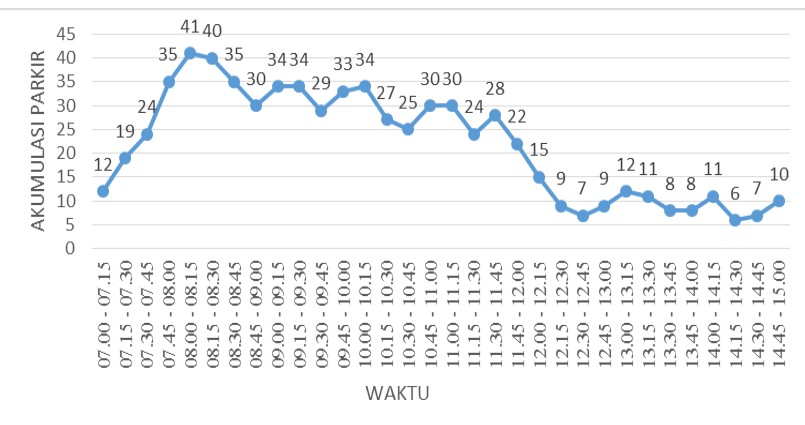

Gambar 8. Grafik Akumulasi Parkir Mobil [2]

Pada Gambar 8 adalah grafik akumulasi pada mobil dari pukul 07.00 - 15.00, dapat dilihat akumulasi tertinggi yaitu sebesar 41 kendaraan

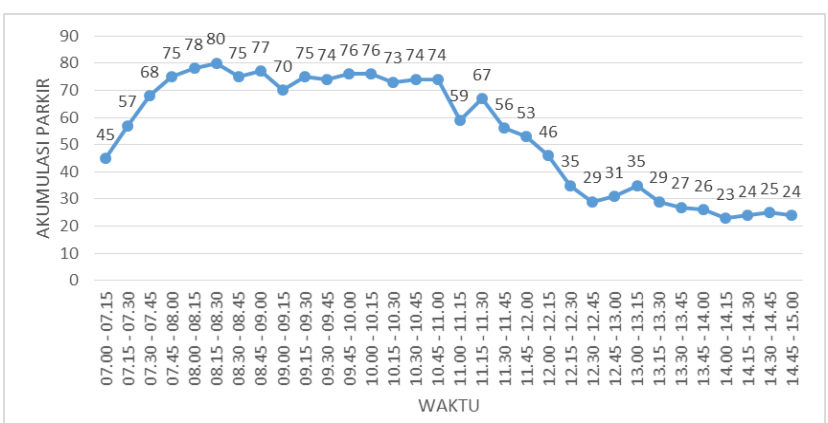

Gambar 9. Grafik Akumulasi Parkir Motor [2]

Dari data diatas dapat diketahui jika akumulasi parkir maksimal mobil terdapat pada pukul 08.00 - 08.15 dengan jumlah 41 mobil dan total volume kendaraan 301 
mobil. Sementara untuk motor, akumulasi parkir maksimal terdapat pada pukul 08.15 - 08.30 dengan jumlah 80 kendaraan dan total volume sebesar 412 kendaraan

\section{E. Turn Over}

Turnover $=$ jumlah total volume parkir Ruang parkir tersedia

$$
=8,85 \text { kendaraan / petak (Mobil) }
$$

Turnover $=$ jumlah total volume parkir Ruang parkir tersedia $=3,05$ kendaraan $/$ petak (Motor)

\section{Indeks Parkir}

Indeks parkir mobil :

Indeks parkir mobil $=\underline{\text { akumulasi parkir } \times 100 \%}$

$$
\text { ruang parkir tersedia }
$$

$$
\begin{aligned}
& =\frac{41 \times 100 \%}{34} \\
& =121 \%
\end{aligned}
$$

Indeks parkir motor:

Indeks parkir mobil = akumulasi parkir $\mathrm{x} 100 \%$

$$
\begin{aligned}
& \text { ruang parkir tersedia } \\
= & \frac{80 \times 100 \%}{135}
\end{aligned}
$$$$
=59,3 \%
$$

\section{KESIMPULAN}

Setelah melakukan analisis perhitungan dan perencanaan, dibuat kesimpulan yang sesuai dengan tujuan dalam studi ini. Berikut adalah uraian kesimpulan studi ini:

1. Dari hasil analisis kapasitas jalan di kawasan Pasar Pucang didapatkan derajat kejenuhan sebesar $0,99 \geq$ 0,75

2. Dari hasil pengolahan data primer yang diperoleh dari pengamatan langsung di lapangan, didapatkan volume total kendaraan yang parkir selama \pm 8 jam pengamatan sebesar 412 motor dan 301 mobil.

Dari hasil analisis didapatkan karakteristik calon pengguna gedung parkir di kawasan Pasar Pucang Surabaya adalah sebagai berikut :Karakteristik pengguna sepeda motor
a. Durasi parkir : 36,65\% ( 15 menit )
b. Akumulasi parkir : 88 motor
c. Pergantian parkir : 3,05 kendaraan /petak
d. Indeks parkir : $58 \%$

Karakteristik pengguna mobil
a. Durasi parkir : 51,51\% ( 15 menit )
b. Akumulasi parkir : 45 mobil
c. Pergantian parkir : 8,85 kendaraan / petak
d. Indeks parkir : $121 \%$

3. Setelah melakukan perhitungan dan didapatkan jumlah demand direncanakan desain gedung parkir sesuai dengan peraturan dan literatur yang ada.

\section{DAFTAR PUSTAKA}

[1] Kementerian Pekerjaan Umum, "Pedoman Kapasitas Jalan Indonesia," Indonesia, 2014.

[2] Direktorat Jenderal Perhubungan Darat, "Pedoman Teknis Penyelenggaraan Fasilitas Parkir,” 1996. 